\title{
A PERCEPÇÃO DA EQUIPE DE ENFERMAGEM SOBRE O MÉTODO CANGURU
}

\author{
THE NURSING TEAM'S PERCEPTION OF THE KANGAROO METHOD
}

\author{
Daniela Gomes Costa ${ }^{1}$ \\ Hosana Oliveira de Castro $^{2}$ \\ Roselane Cristina Passos ${ }^{3}$ \\ Patrícia Archanjo Lopes ${ }^{4}$ \\ Vitor Hugo Nascimento Firmino ${ }^{5}$
}

RESUMO: O Método Canguru é um tipo de assistência neonatal que implica o contato pele a pele precoce entre a mãe e o recém-nascido de baixo peso, de forma crescente e pelo tempo que ambos entenderem ser prazeroso e suficiente, permitindo, dessa forma, uma maior participação dos pais no cuidado ao seu recém-nascido. Para que isso ocorra de forma efetiva, é necessária uma equipe de enfermagem qualificada para orientar a mãe e a família em todas as etapas do método. Sob essa perspectiva, o estudo compara o conhecimento da equipe de enfermagem sobre o Método Canguru com a literatura, a fim de compreender a percepção dos entrevistados sobre o tema. A pesquisa foi delineada por um estudo descritivo, exploratório, de abordagem qualitativa, em que a coleta de dados ocorreu no Hospital Materno Infantil de Brasília, durante o primeiro semestre de 2021. A partir disso, concluiuse que a equipe de enfermagem apresentou conhecimento geral, entretanto, alguns aspectos não condizem com os parâmetros apresentados pelos estudos nacionais.

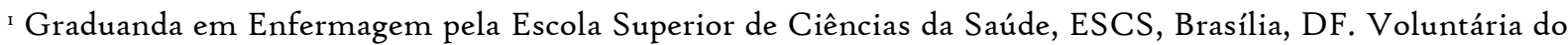
Programa de Iniciação Científica da Fundação de Ensino e Pesquisa em Ciências da Saúde, FEPECS. E-mail: daniela.costaal@escs.edu.br https://orcid.org/oooo-ooor-5710-2196

${ }^{2}$ Graduanda em Enfermagem pela Escola Superior de Ciências da Saúde, ESCS, Brasília, DF. Bolsista pelo Programa de Iniciação Científica do Conselho Nacional de Desenvolvimento Científico e Tecnológico, FEPECS.E-mail: hosana.castroal@escs.edu.br https://orcid.org/oooo-ooo2-6619-4763

3 Graduação em Enfermagem pela Universidade Paulista (2007). Especialização e Experiência na área de Enfermagem. Especialista em Saúde Pública com ênfase na saúde da família pela faculdade EUROBRAS. Lotada no Hospital Materno Infantil de Brasília, HMIB, e na Escola Superior de Ciências da Saúde, ESCS, como Docente do Curso de Graduação em Enfermagem. E-mail: roselane.oliveira@escs.edu.br https://orcid.org/oooo-ooor-9268-5892

${ }^{4}$ Graduação em $\quad$ Enfermagem $\quad$ pela Universidade Federal de Goiás, UFG, Brasil. Possui bacharelado e licenciatura em enfermagem pela Universidade Federal de Goiás (2005), especialização em Acupuntura e em Ginecologia e Obstetrícia, mestranda pela Universidade de Brasília, UnB. Faz parte do quadro de enfermeiros da SVS/DIVEP/GECAMP/CIEVS pela Secretaria de Saúde do Distrito Federal. E-mail: patricia.lopes@escs.edu.br https://orcid.org/oooo-ooo2-8766-1252

5 Graduação em Enfermagem pela Escola Superior de Ciências da Saúde, ESCS. Colaborador da Liga Acadêmica de Parto Humanizado (LAPH-ESCS), pós-graduando em Enfermagem em Urgência e Emergência pela UNIEURO, pesquisador na área de Gênero e Saúde. E-mail: vitorhnf.escs@gmail.com http://orcid.org/oooo-ooo2-5177-2903.
} 
Palavras-chaves: pediatria. neonatologia. enfermagem. Método Canguru.

ABSTRACT: Kangaroo Method is a type of neonatal care that involves early skin-to-skin contact between the mother and the low birth weight newborn, increasingly and for as long as both consider it pleasurable and sufficient, thus allowing greater participation of parents in the attention of their newborn. A qualified nursing team is needed to guide the mother and family at all stages of the method for this to happen effectively. From this perspective, the study compares the knowledge of the nursing staff about the Kangaroo Method with the literature, to understand the perception of interviews on the subject. The research was designed by a descriptive, exploratory study with a qualitative approach, in which data collection took place in the Hospital Materno Infantil de Brasília, during the first semester of 202I. From this, it was concluded that the nursing team had general knowledge, however, some aspects do not match the parameters presented by national studies.

Keywords: pediatrics. neonatology. Nursing. Kangaroo Method.

\section{INTRODUÇÃO}

Idealizado na Colômbia, em 1979, pelo Instituto Materno Infantil de Bogotá, o Método Canguru (MC) tinha como proposta inicial reduzir a superlotação das Unidades Neonatais, visando atender à falta de incubadoras. Por muito tempo, essa forma de atendimento foi vista como uma alternativa encontrada pelos países subdesenvolvidos e em desenvolvimento para baratear o custeio do atendimento oferecido aos recém-nascidos. No entanto, atualmente, sabe-se que o Método é um importante aliado para a melhoria da assistência obstétrica e neonatal, fundamentada no princípio de atenção humanizada (BRASIL, 2017).

No âmbito brasileiro, a implantação do MC se iniciou com a Conferência Nacional Método Canguru e foi efetivada pela Portaria ${ }^{\circ}$ 693, de 2000, a qual o define como:

\footnotetext{
Um tipo de assistência neonatal que implica o contato pele a pele precoce entre a mãe e o recém-nascido de baixo peso, de forma crescente e pelo tempo que ambos entenderem ser prazeroso e suficiente, permitindo, dessa forma, uma maior participação dos pais no cuidado ao seu recém-nascido (BRASIL, 200o).
}

Conforme destacado na Portaria 693/200o, a implantação do MC ocorre em três etapas: a primeira compreende a identificação da gestação de alto risco, internação na UTI e adaptação à vida extra-uterina; a segunda necessita da estabilidade clínica da criança e disponibilidade da mãe para iniciar a posição canguru; e a terceira é a fase domiciliar, no qual exige um acompanhamento ambulatorial e criterioso após a alta hospitalar. 
Além do contato pele a pele, há também uma amamentação precoce do bebê prematuro, geralmente iniciada durante a segunda etapa do processo. Para Leite et al. (2019), a separação do binômio mãe-filho, imposta nas UTI convencionais, pode representar risco elevado de desmame precoce, devido a fatores biológicos como aglactação (falta do leite materno), ou fatores psicológicos da mãe que se sente insegura em relação à amamentação, o que pode prejudicar a formação do vínculo afetivo e a interação entre a família e a criança, fundamental para atenuar ou acentuar as dificuldades próprias dessa condição de vulnerabilidade do neonato.

Posto isto, é importante salientar a participação do profissional de enfermagem no acompanhamento de todas as etapas e no apoio biopsicológico do binômio, sendo fundamental para a execução do processo. Segundo Carvalho, Maia e Costa (2018), a enfermagem realiza os cuidados individualizados, orienta a importância do aleitamento materno exclusivo, interage com a família e estimula a participação dos pais no cuidado, melhorando o vínculo entre eles e o bebê. Conforme destacado pelas autoras, a atuação da equipe de enfermagem é de extrema importância, por meio do cuidado humanizado, atento e acolhedor, esclarecendo as possíveis dúvidas e dificuldades encontradas na utilização do método.

O MC apresenta vários benefícios, tais como a diminuição das infecções hospitalares e do tempo de permanência hospitalar do neonato. Apesar disso, percebe-se uma resistência na adoção do processo por parte dos profissionais de saúde, favorecendo o prolongamento dos períodos de internação. Essa resistência é derivada da fragilidade no conhecimento sobre o impacto do Método Canguru, na vida dos recém-nascidos e de seus familiares (FERREIRA et al., 2019).

Nesse contexto, é fundamental que os profissionais de enfermagem envolvidos no processo tenham conhecimentos apropriados para o estabelecimento de todas as etapas do Método. Dessa forma, foi estabelecido o objetivo do estudo que visa compreender a percepção dos enfermeiros quanto ao Método Canguru e seus benefícios.

\section{METODOLOGIA}


A pesquisa tem como abordagem a investigação qualitativa. Esta não requer o uso de métodos e técnicas estatísticas. $\mathrm{O}$ ambiente natural é a fonte direta para coleta de dados e o pesquisador é o instrumento-chave. O pesquisador mantém contato direto com o ambiente e o objeto de estudo em questão, necessitando de um trabalho mais intensivo de campo e pesquisas de caráter descritivo (PRODANOV; FREITAS, 2013).

A coleta de dados foi realizada na Unidade Neonatal do Hospital Materno Infantil de Brasília (HMIB), durante o primeiro semestre de 2021. O estudo incluiu enfermeiros e técnicos de enfermagem que atenderam aos critérios de inclusão: ter atuação na unidade de Terapia Intensiva Neonatal (UTIN) e/ou Unidade de Cuidados Intermediários Neonatal (UCINCo) e já ter tido alguma experiência com o Método Canguru.

Todos os participantes envolvidos foram abordados durante seu turno de trabalho, de acordo com a rotina do local, a partir da apresentação dos objetivos da pesquisa. Cada entrevista teve duração média de io minutos, sendo composta por quatro questões: $\mathrm{O}$ que você compreende ser o Método Canguru? O que você compreende ser o papel do enfermeiro no Método Canguru? Quais benefícios você acha que o Método Canguru oferece ao recémnascido? Quais são os efeitos que você acredita que Método Canguru provoque na família do neonato? A coleta de dados foi encerrada quando os limites dos recursos disponíveis foram alcançados.

Após as entrevistas, as gravações foram transcritas em sua íntegra, assegurando a fidedignidade dos conteúdos discursivos. Com objetivo de garantir a privacidade dos entrevistados, foi utilizado a letra $\mathrm{E}$ para os enfermeiros e o TE, para os técnicos de enfermagem, ambos seguindo um número sequencial à entrevista realizada (EI, E2...). A análise do conteúdo procedeu segundo o método de Bardin, o qual é organizado em três fases: pré-análise, exploração do material e tratamento dos resultados, inferência e interpretação (BARDIN, 2016).

A fase da pré-análise tem como objetivo organizar o material pertinente à pesquisa, em que ocorrerá a escolha dos documentos, a elaboração das hipóteses e objetivos, para enfim preparar o material. Quando a pré-análise é concluída, a exploração do material irá aplicar sistematicamente as decisões tomadas, incorporando operações como a codificação. No 
tratamento dos resultados obtidos põe-se em relevo e constata-se as informações fornecidas pela análise, por meio de operações estatísticas (BARDIN, 2016).

O estudo foi submetido ao Comitê de Ética e Pesquisa da Secretaria de Estado de Saúde do Distrito Federal (CEP-SES/DF) e aprovado sob Parecer Consubstanciado no 4.424.734, CAAE 39810520.4.0000.5553. Foi definido como patrocinador principal a Fundação de Ensino e Pesquisa em Ciências da Saúde (FEPECS). Respeitaram-se os requisitos estabelecidos pela Resolução no 466/12 do Conselho Nacional de Saúde (CNS), que dispõe sobre as normas e diretrizes que regulamentam as pesquisas envolvendo seres humanos.

\section{RESULTADOS E DISCUSSÃO}

Ao questionar os entrevistados sobre o que compreendem ser o conceito e os componentes do Método Canguru, a maioria dos enfermeiros (61\%; $n=13)$ e dos técnicos de enfermagem $(58 \% ; n=23)$ descreveram-no como uma técnica a qual objetiva humanizar a assistência ao recém-nascido e aumentar o vínculo entre o bebê e os pais, além de promover o desenvolvimento biopsicossocial e o conforto do neonato, por meio do contato pele a pele e

da Foram convidados 68 profissionais de enfermagem, destes, 6o aceitaram participar da pesquisa e 8 se recusaram, sendo 7 técnicos de enfermagem e I enfermeiro. Dentre os participantes, 59 eram do sexo feminino, representando $98,3 \%$ dos entrevistados, e r era do sexo masculino. Desse total, 2i eram enfermeiros (35\%) e 39 eram técnicos de enfermagem (65\%). Quanto à unidade de atendimento onde os enfermeiros atuam, tem-se que 4 trabalhavam na Unidade de Cuidado Intermediário Neonatal (19\%) e 17 trabalhavam na Unidade de Terapia Intensiva Neonatal (81\%). Com relação aos técnicos de enfermagem, sabe-se que 2 atuavam na Unidade de Cuidado Intermediário Neonatal (5,1\%) e 37 trabalhavam na Unidade de Terapia Intensiva Neonatal (94,9\%). Destes, todos, enfermeiros e técnicos de enfermagem, relataram ter experiência com o Método Canguru através de cursos fornecidos pela Instituição, por estudos prévios ou pela experiência profissional.

Após a transcrição, seguiram-se as etapas de codificação proposta por Bardin (2016), assim, as falas dos sujeitos entrevistados foram analisadas e localizadas em unidades de registro que continham significado relacionado ao objeto do estudo. Essas unidades foram agrupadas em 6 categorias, sendo elas: (I) Promoção do Método; (2) benefícios psicoafetivos 
para o RN; (3) benefícios biológicos ao $\mathrm{RN}$; (4) benefícios do método para a família e (5) responsabilidades da equipe de enfermagem na aplicação do $\mathrm{MC}$ e (6) barreiras.

\section{Categoria "Promoção do Método"}

Ao questionar os entrevistados sobre o que compreendem ser o conceito e os componentes do Método Canguru, a maioria dos enfermeiros (6r\%; $n=13)$ e dos técnicos de enfermagem $(58 \% ; n=23)$ descreveram-no como uma técnica a qual objetiva humanizar a assistência ao recém-nascido e aumentar o vínculo entre o bebê e os pais, além de promover o desenvolvimento biopsicossocial e o conforto do neonato, por meio do contato pele a pele e da participação dos pais nos cuidados perinatais em ambiente adequado. Constata-se concordância entre esses relatos e os preceitos e objetivos do Método Canguru.

Eu acredito que sejam atitudes, ações que a gente provoque humanização no
cuidado inserindo a mãe no cuidado, na participação dos procedimentos, como a
pulsão e o curativo, se ela estiver ali do lado, pedir para.... Ajudar a segurar o bebê,
falando com ele, tentando aproximá-la o máximo possível da assistência de
enfermagem." (EIS)

Cerca de 38\% $(n=8)$ dos enfermeiros e 33\% ( $n=13)$ dos técnicos de enfermagem resumiram o método à posição canguru, focando somente no cuidado hospitalar, sendo assim observa-se uma lacuna de conhecimento nesses profissionais, já que o MC não se restringe à posição canguru.

O método canguru consiste em colocar o bebê de baixo peso, né? Em contato pele a pele com a mãe, pai ou algum familiar." (Trg)

Ao contrário do que os entrevistados relataram, o MC ultrapassa a posição canguru e o pele a pele, uma vez que o recém-nascido pode ser colocado em PC somente após estabilização. Dessa forma, o método abrange ações que envolvam o acolhimento, a aproximação dos pais com o RN, o estímulo ao toque e as orientações no pós-parto imediato à mãe e aos familiares. Todas essas ações têm como objetivo humanizar a assistência perinatal (PINAFFI, 2018). A humanização demonstra o comprometimento não apenas com as dimensões técnicas e práticas do trabalho, mas também com as dimensões subjetivas e sociais da vida, sendo assim, humanizar a assistência integral promove a criação de relações de encontro e acolhimento entre os familiares e o $\mathrm{RN}$ em ambientes compatíveis com o 
período neonatal, tendo como facilitadores profissionais com segurança técnica (SILVA; BARROS; NASCIMENTO, 2014; PINAFFI, 2018).

Além disso, em relação às etapas do $\mathrm{MC}$, contatou-se que a minoria dos enfermeiros $(23 \% ; n=5)$ e dos técnicos de enfermagem $(2 \% ; n=1)$ citaram as três etapas.

O Método Canguru é uma estratégia composta por três etapas... não me lembro exatamente os três..., mas que a terceira etapa termina em casa e recebe alta em

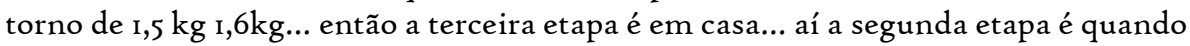
ele atinge esse peso de 1,5 a I,6 kg e aí ele fica sempre em contato com a mãe, a gente tenta aumentar o vínculo da criança." (E9)

Segundo o Ministério da Saúde (2017), o Método Canguru é uma estratégia de atenção ao recém-nascido humanizada e qualificada, no qual intervém-se em seus fatores biopsicossociais, a fim de favorecer o cuidado perinatal e familiar. Esse cuidado permite a participação da família nos cuidados neonatais, estando presente o contato pele a pele, que deve ser iniciado de forma precoce.

A primeira fase inicia-se no pré-natal de alto-risco com a observação da possibilidade de nascimento prematuro e/ou baixo peso, seguido da internação do RN em UTI ou na Unidade de Cuidado Intermediário Neonatal Convencional (UCINCo), onde ocorrerá a primeira aproximação dos pais e familiares com seus bebês. Nesta etapa, é preciso garantir a puérpera permanência hospitalar nos primeiros cinco dias e o suporte necessário para estadia, além de estimular o livre acesso do companheiro ou acompanhante materno nos cuidados gestacionais e perinatais. A partir desse momento, incentiva-se o contato pele a pele e a amamentação precoce, respeitando as condições clínicas do $\mathrm{RN}$ e a disponibilidade de aproximação dos pais com o neonato (BRASIL, 2017; 2007).

A Portaria n ${ }^{\circ} .683$ de 2007 do Ministério da Saúde determina que durante a segunda etapa, que ocorre na UCINCo, a mãe permanecerá em tempo integral com o recém-nascido, em alojamento conjunto, e a posição canguru será realizada pelo maior tempo possível, assegurando-lhes todos os cuidados iniciados na primeira etapa, principalmente o aleitamento materno. $\mathrm{O}$ neonato permanece nesta etapa quando apresenta estabilidade 
clínica, peso mínimo de I.25og e nutrição enteral plena (peito, sonda gástrica ou copo). Esta etapa funcionará como uma pré- alta hospitalar (BRASIL, 2017).

De acordo com o Ministério da Saúde (2017), a alta hospitalar, terceira etapa, é realizada quando o bebê atinge o peso mínimo de $\mathrm{I} .600 \mathrm{~g}$, em que seu ganho de peso é adequado e a mãe está segura quanto aos cuidados neonatais, bem orientada e seus familiares estão conscientes sobre os cuidados domiciliares do bebê. Dessa forma, o acompanhamento da criança e da família será realizado no domicílio ou no ambulatório, dando continuidade à abordagem biopsicossocial iniciada na primeira etapa. No momento em que o bebê completa 2.500g, se seguirão as normas de crescimento e desenvolvimento do Ministério da Saúde. Para garantir os resultados positivos do Método, a etapa ambulatorial/residencial deve contar com uma equipe multiprofissional composta por enfermeiros, fisioterapeutas, médicos, psicólogos, nutricionistas, fonoaudiólogos e assistentes sociais (SILVA; BARROS; NASCIMENTO, 2014).

Os relatos dos enfermeiros e técnicos sobre o MC seguem o mesmo padrão de estudos realizados anteriormente. Os participantes destes estudos, assim como os entrevistados da presente pesquisa, destacaram o MC como um modelo de humanização para assistência ao RN e sua família, com objetivo de fortalecer o vínculo da tríade mãe-pai-bebê e proporcionar melhora no desenvolvimento do neonato. Quanto às etapas do Método, no presente artigo, foram encontrados défices de conhecimento semelhantes aos estudos nacionais, fato que pode ser relacionado às deficiências curriculares e à falta de preparo de profissionais para essa prática assistencial (SILVA; BARROS; NASCIMENTO, 20I4; FERREIRA et al., 2019).

\section{Categoria "Benefícios psicoafetivos para o RN"}

Quando definiram os benefícios do MC, os entrevistados usaram palavras como "laços afetivos" e "tranquilidade" para qualificar o processo psicoafetivo que envolve o neonato. Para esses profissionais, a incubadora tradicional limita o contato pele a pele, sendo o método canguru um meio que propicia o aumento dos laços entre o binômio mãe-bebê, 
uma vez que simula a situação intrauterina da criança. Tais questões podem ser evidenciadas em falas como a transcrita abaixo:

[...] ele auxilia nos laços afetivos da mãe com o bebê... Porque assim, os bebês ficam muito tempo sozinhos na UTI neonatal e eles ficam muito tempo lá na incubadora. Com o método canguru, as mães ficam um pouco com eles e fazem até três vezes ao dia... Assim, né? O tempo que ela tiver livre, ela pode fazer" (Ti2).

Nesse sentido, tem-se que $76,2 \%(n=16)$ dos enfermeiros e cerca de $52,8 \%(n=21)$ dos técnicos de enfermagem apontaram o vínculo como principal benefício psicoafetivo que o MC proporciona para o RN e para a família.

[...] quanto mais tempo essa criança tiver contato com a mãe, mais esse vínculo é fortalecido, porque assim... Quando o bebê nasce normal, a mãe fica com o bebê, vai para casa, leva o bebê para família tem tudo aquilo. Quando o bebê nasce prematuro, tudo isso é quebrado, porque ele nasce e em seguida são separados, geralmente o bebê vai para UTIN e a mãe para enfermaria, então eles são separados... houve essa quebra... e a gente precisa fortalecer esse vínculo o mais precocemente possível. Então o pele-a-pele, a posição canguru, tem que começar já na UTIN, assim que o bebê estiver estável” (Eıo)

Em consonância com os transcritos, o Ministério da Saúde (2017) afirma que a internação de um recém-nascido em uma unidade neonatal representa uma situação de crise no bem-estar e no conforto das relações familiares, uma vez que interfere na história desejada entre os pais e o bebê, aumentando os desafios para a formação e o estabelecimento de vínculo afetivo entre os familiares. Nesse sentido, Maia et al. (2012) aborda o MC como um meio para proporcionar estímulos necessários para a formação e ampliação do vínculo afetivo.

Além disso, em uma pesquisa com 488 mães de bebês prematuros, observou-se que aquelas que participavam do MC tinham melhor percepção sobre o bebê, mais segurança nos cuidados e menos sentimentos de estresse mesmo quando a estadia hospitalar foi prolongada. Esses sentimentos podem ser pontos que afetam indiretamente na formação do vínculo, sendo, portanto, indicadores positivos dos benefícios psicoafetivos promovidos pelo MC (TESSIER et al. 1998 apud VENÂNCIO e ALMEIDA, 2004).

Tais vantagens também foram identificadas durante a coleta de dados, sendo evidenciadas em falas como:

[...] o Método Canguru deixa tanto o pai quanto a mãe mais empoderados, mais fortalecidos, porque tem o receio, por ser um bebê prematuro, que ele seja mais 
frágil do que os outros bebês que nasceram no tempo certo. Então quando a gente traz tanto a posição canguru como os outros benefícios, essa família fica mais segura com o cuidado desse bebê" (Еıо)

Dessa forma, pode-se observar que as respostas apresentadas pelos profissionais de enfermagem seguiram o padrão dos estudos realizados anteriormente, abordando a criação de laços afetivos, as melhorias emocionais e a formação do vínculo como os principais benefícios psicoafetivos para o RN.

\section{Categoria "Benefícios biológicos ao RN"}

Quando questionados sobre os benefícios que o método proporciona ao $\mathrm{RN}$, aproximadamente $57 \%(n=12)$ dos enfermeiros e 49\% (n=19) dos técnicos de enfermagem citaram benefícios biológicos, como controle térmico e desenvolvimento dos sistemas corporais. Dentre esse grupo, cerca de $42 \%(n=13)$ dos profissionais elencaram melhora na proteção do recém-nascido através do desenvolvimento do sistema imunológico, visto que o contato pele a pele permite a interação com a microbiota materna, como pode ser identificado a seguir:

[...] a posição canguru é confortável para o bebê, ele se sente quentinho, então ajuda no controle térmico do bebê [...] outra questão importante é que a mãe passa a flora da pele dela para o bebê e isso protege a pele dele contra outras infecções." ( $\left.E_{3}\right)$

Além disso, outros benefícios foram identificados pelos profissionais de enfermagem, evidenciando a estabilidade das funções fisiológicas através da melhora na frequência cardíaca, do alívio da dor, da termorregulação e da melhora na respiração do neonato. Tais questões podem ser evidenciadas em falas como a transcrita abaixo:

[...] vai proporcionar para o bebê melhora da frequência respiratória, da irritabilidade, do choro, da frequência cardíaca e fortalecer o vínculo familiar com o bebê." (T 34)

Nesse sentido, o estudo realizado por Santos e Filho (2016) identificou que o MC proporciona homeostase, menor perda de calor e redução dos riscos de infecção hospitalar. Outra informação importante apontada pelo artigo e que condiz com os relatos dos profissionais é a influência satisfatória nas variáveis respiratórias, uma vez que a posição auxilia na eficiência do diafragma e da função pulmonar, diminuindo as assincronias 
toracoabdominais dos neonatos com dificuldades, favorecendo a oxigenação e promovendo estabilidade cardiorrespiratória. Além disso, os movimentos respiratórios maternos estimulam o recém-nascido pré-termo (RNPT) a respirar, promovem maior tempo de sono não REM e estímulo proprioceptivo. Também é hipotetizado que o estímulo olfatório com odor agradável reduziria os episódios de apneia e bradicardia (BRASIL, 2017).

Ademais, o estudo de Calado et. al. (2019) também vai ao encontro dos transcritos quando afirma que a posição canguru diminui a dor durante as intervenções no qual o recémnascido é submetido. Nesse mesmo ponto de vista, a revisão realizada por Lotto e Linhares (2018) aponta que o MC é uma estratégia não farmacológica para o alívio da dor durante o tratamento intensivo na fase neonatal, sendo, portanto, um meio de diminuir respostas exageradas por parte do bebê quando realizados procedimentos que estimulem a nocicepção.

Com relação à termorregulação, Freitas et al. (2020) aponta que o MC é uma forma de manter o bebê aquecido com o calor materno. Estudos recentes demonstraram que a manutenção da temperatura corporal obtida pelo MC é semelhante à das incubadoras convencionais . A importância de manter a temperatura de bebês prematuros está no fato de que apresentam mais facilidade para perda de calor em relação aos bebês a termos, uma vez que apresentam baixa porcentagem de tecido adiposo, sendo comum apresentarem hipotermia. Importante ressaltar, que devido à instabilidade do controle térmico do RN, este não sofre apenas hipotermia, mas também pode sofrer hipertermia por superaquecimento. Assim, o método implica diretamente no controle térmico do recém-nascido (BRASIL, 2017).

Dessa forma, observa-se que os relatos dos profissionais de enfermagem sobre o MC seguem o mesmo padrão de estudos realizados anteriormente, elencando benefícios como desenvolvimento do sistema imune e do sistema respiratório, alívio da dor e termorregulação.

\section{Categoria "Benefícios do método para a família"}

A maioria dos enfermeiros entrevistados (95\%; $n=20$ ) relataram a promoção do vínculo entre o bebê e a família como principal benefício do MC. Outros benefícios também foram pontuados, como o estímulo à amamentação $(19 \% ; n=4)$, ao afeto entre família-bebê 
( $5 \% ; n=1)$, à tranquilidade da mãe e família $(19 \% ; n=4)$ e à unidade familiar $(10 \% ; n=2)$. Também se pontuou o desenvolvimento da parentalidade e da confiança dos pais, em virtude da participação familiar nos cuidados neonatais, fazendo com que a adaptação às necessidades do bebê seja facilitada.

Para a família é, principalmente, eles se sentirem parte do tratamento do bebê. [...] Então, o método canguru vai permitir que a família se sinta parte do tratamento e se sinta importante nesse momento, participando também deste cuidado. ” (E2)

Assim como os enfermeiros, grande parte dos técnicos de enfermagem $(82 \% ; n=32)$ destacaram a criação do vínculo família-bebê como o benefício principal. Além disso, foram relatados benefícios semelhantes às entrevistas com enfermeiros, entretanto, I0\% $(n=4)$ dos técnicos de enfermagem apresentaram baixo conhecimento sobre o tema, não conseguindo responder à questão, o que evidencia uma carência de conhecimento.

Uma vez que este bebê está mais tranquilo, a sua família também vai estar. Consequentemente, com todos tranquilos, a mãe vai ter condições de amamentar o seu filho... É... ela vai se sentir mais segura e mais próxima do seu bebê, né? E em relação ao leite também, favorece a descida de leite porque o bebê vai estar mais próximo do seio, vai estimular e tudo mais, né? Vai favorecer a descida de leite." (Tig)

O benefício destacado pelos entrevistados está em concordância com a literatura, pois o MC atua estimulando o vínculo família-bebê, por meio da participação dos pais nos cuidados do $\mathrm{RN}$, o que os ajuda na construção da parentalidade e formação de vínculo afetivo. A posição canguru promove o desenvolvimento espontâneo dos laços afetivos, permitindo que os pais possam ter um contato íntimo com o $\mathrm{RN}$, dando-lhes mais confiança. Com o desenvolvimento do vínculo, os pais passam a perceber as mímicas faciais do neonato e sua singularidade, além de estimular o aleitamento materno exclusivo (BRASIL, 2017).

Em relação aos sentimentos maternos, Heck et al. (2016) constatou que as mães participantes do MC sentiram-se mais valorizadas por participarem ativamente do cuidado dos RNs, além de desenvolverem a noção de sua importância como cuidadora e facilitadora do crescimento e desenvolvimento de seu bebê. Anteriormente, no estudo de Cruvinel e Macedo (2007) as mães participantes do MC relataram estarem mais confiantes, alegres, competentes e com ideias mais claras após visitarem seu filho. 
Dessa forma, o MC proporciona benefícios que vão além do cuidado intrahospitalar, pois o aumento do vínculo pai-mãe-bebê faz com que a mãe se sinta mais encorajada a continuar o aleitamento materno, além de os pais sentirem-se mais preparados e seguros às situações adversas, já que puderam participar do período de internação de seu filho, por meio da observação e execução dos cuidados prestados ao $\mathrm{RN}$, tendo como resultado o empoderamento familiar (HECK et al., 2016).

\section{Categoria "Responsabilidades da equipe de enfermagem na aplicação do MC"}

Quando questionados sobre o papel da equipe de enfermagem na aplicação do MC, $60 \%(n=36)$ dos profissionais usaram termos como "orientação" e "estímulo" para definir as responsabilidades da categoria. Essas palavras estavam associadas à execução adequada do método, aos benefícios ofertados por ele e à amamentação, podendo ser observadas na fala abaixo:

papel da equipe de enfermagem seria orientar a mãe com relação aos benefícios e a importância do método e ajudar na aplicação do método, para que elas consigam fazer adequadamente e se sintam mais à vontade também." ( $\left.\mathrm{T}_{27}\right)$

Ao encontro dos transcritos, o estudo de Souza et al. (2016) cita como atribuições da equipe de enfermagem: agilizar e incentivar o contato da mãe com o recém-nascido, o mais precoce possível na unidade neonatal; orientar quanto aos cuidados básicos; e estimular e orientar quanto à posição Mãe-Canguru. Além disso, o Ministério da Saúde (2017, p. 315) encoraja o trabalho multiprofissional para dar suporte emocional e desenvolver ações educativas e atividades recreativas para os pais durante o período de permanência hospitalar. Nesse sentido, o MC possui um amplo espaço de atuação da enfermagem na assistência ao recém-nascido.

Para Bork e Santos (2012), a proposta da humanização do cuidado ao RN prematuro é fundamental, pois a necessidade de o bebê receber cuidados em uma UTIN representa uma quebra de expectativas relacionada à maternidade e ao medo da morte da criança. Por esse viés, em todos esses momentos de dificuldades, acredita-se que a equipe de enfermagem tenha um papel determinante ao favorecer o acolhimento das famílias, informar-lhes sobre o estado de saúde dos bebês e facilitar a adaptação das mães e familiares durante a internação. 
Além disso, em observação ativa, a prática dentro da unidade de referência estimula a participação paterna no MC. No entanto, isso foi citado como uma responsabilidade da equipe de enfermagem em apenas uma fala:

O papel da enfermagem, já que nós ficamos mais perto do paciente e dos pais, é ter essa sensibilidade de enxergar a importância do método e fazer. Se o bebê estiver estável, a gente coloca na mãe e também no pai, que muitas vezes fica um pouco de lado por causa dos cuidados. Então nosso papel é olhar para ele também.” (EII)

Nesse sentido, o estudo de Lopes et al. (2019) aborda a figura paterna como imprescindível para o restabelecimento da estrutura familiar. Assim, as autoras citam como responsabilidade dos profissionais de saúde, em especial da enfermagem, entender a intersubjetividade do pai com o recém-nascido prematuro, suas atitudes e anseios frente ao cuidado com o filho, a fim de melhorar a assistência em todas as fases que permeiam o MC.

Outrossim, segundo Bernardo et al. (2015), as mulheres que acabam de ter os seus bebês, encontram-se, elas mesmas, necessariamente em estado de dependência. Para desempenhar bem a sua tarefa, ela necessita de uma rede de apoio que a auxilie no cuidado do RN. Dessa forma, quando a equipe de enfermagem não estimula a participação paterna no Cuidado Canguru, a mãe fica sobrecarregada e o pai passa a ser visto como coadjuvante do processo.

\section{Categoria "Barreiras"}

Além dessas categorias, foram relatadas algumas barreiras pelos enfermeiros e técnicos para aplicação do método, entre elas, estão: o medo dos pais ( $9 \%$ dos enfermeiros), o elevado peso do RN (5\% dos técnicos), a pandemia de Covid-19 (4\% dos enfermeiros), o estado de gravidade do bebê ( $4 \%$ dos enfermeiros) e a resistência materna à posição canguru (2\% dos técnicos).

(...) acaba que mãe tem medo de tocar no recém-nascido, que está cheio de dispositivos, que é muito frágil, que tem manipulação mínima... De estimular e auxiliar nesse sentido, de oferecer suporte, de ajudar a pegar mesmo o bebê." (EII)

\section{CONCLUSÃO}

Através dos depoimentos dos profissionais de enfermagem que participaram desta pesquisa, nota-se que os conhecimentos acerca dos benefícios propiciados pelo MC são 
satisfatórios, uma vez que seguem o mesmo padrão de estudos realizados anteriormente. Nesse agrupamento, os profissionais citaram: criação de laços afetivos, formação de vínculo, melhoria dos sistema imune e respiratório, alívio da dor e termorregulação; enfatizando que os benefícios ultrapassam o cuidado intrahospitalar através do empoderamento familiar.

Apesar do conhecimento ser suficiente, alguns aspectos não condizem com os parâmetros apresentados pelos estudos nacionais, dentre eles: as etapas do MC, que neste estudo foram limitadas à posição canguru; e à estimulação da participação paterna, que não foi considerada como uma responsabilidade da equipe de enfermagem.

Dessa forma, os resultados sugerem a necessidade da implantação de ações de educação continuada para melhorar a qualidade da assistência de enfermagem durante a aplicação do método na instituição.

\section{REFERÊNCIAS}

BARDIN, L. Análise de conteúdo: edição revista e ampliada. São Paulo: Edições 7o, 2016.

BERNARDO, F. R.; ZUCCO, L. P. “A centralidade do feminino no Método Canguru”. Rev. Sexualidad, salud y sociedad, 2015. https://doi.org/10.1590/1984-6487.sess.2015.21.09.a

BORK, M; SANTOS, E. K. A. Método canguru: práticas investigativas e de cuidado de enfermagem no modelo de adaptação de Roy. Esc. Anna Nery. Rio de Janeiro, v.ı, n.2, p.263-69. 2012. Disponível em: < http:///C:/Users/Alexandre/Downloads/54I-I-I209-I-Io20170809.pdf $>$. Acessado em: 2I julho 202I.

BRASIL. MINISTÉRIO DA SAÚDE. Portaria GM n. 693, Norma de orientação para a implantação do método canguru. Diário Oficial da União, os de julho de 2000. 
BRASIL. MINISTÉRIO DA SAÚDE. Secretaria de Atenção à Saúde. Departamento de Ações Programáticas Estratégicas. Atenção humanizada ao recém-nascido : Método Canguru : manual técnico / Ministério da Saúde, Secretaria de Atenção à Saúde, Departamento de Ações Programáticas Estratégicas. - 3. ed. - Brasília : Ministério da Saúde, 2017

CALADO, Bárbara Pulido. AlULAS, Gabriela Oia de. MONTES, Daniela Cristina. História, implantação no Brasil e benefícios do método canguru: Revisão integrativa da literatura. Revista Científica Multidisciplinar Núcleo do Conhecimento. Ano 04, Ed. o6, Vol. 03, pp. 14-34.Junho de 2019. ISSN: 2448-0959

CARVAlHO, Elicássia Thayná da Silva. MAIA, Fabiula Souza. COSTA, Ruth Silva Lima.

Método Canguru: o papel do enfermeiro frente aos cuidados de enfermagem. Revista Dê Ciência Uninorte, 2018.

CONSELHO NACIONAL DE SAÚDE; Ministério da Saúde Resolução nº 466/2012.

CRUVINEL, F. G.; MACEDO, E. C. Interação mãe-bebê pré-termo e mudança no estado de humor: comparação do Método Mãe-Canguru com visita na Unidade de Terapia Intensiva Neonatal. Rev. Bras. Saude Mater. Infant. 7 (4). Dez 2007. https://doi.org/I0.1590/S1519-38292007000400012

FERREIRA, D. O. et al. Método canguru: percepções sobre o conhecimento, potencialidades e barreiras entre enfermeiras. Esc. Anna Nery; 2019. https://doi.org/ro.1590/2177-9465-ean2019-0100

FREITAS et al. Os benefícios do método canguru e a assistência de enfermagem. Brazilian Journal of Surgery and Clinical Research. Vol.3I,n.2,pp.Io6-II2. Jun - Ago 2020

GABINETE DO MINISTRO. Ministério da Saúde. Portaria n ${ }^{\circ}$ I.683, de I2 de julho de 2007 
GOULART, Bethania Ferreira. AMARAL, Jesislei Bonolo. COUTIM, Divanice. Método canguru: percepções sobre o conhecimento, potencialidades e barreiras entre enfermeiras. Scielo Saúde Pública, 2019. https://doi.org/ı.1590/2177-9465-ean-2019-oroo

HECK, G. M. M. et al. Compreensão do sentimento materno na vivência no Método Canguru. Rev Enferm UFSM 2016 Jan./Mar.;6(I): 71-83. https://doi.org/10.5902/2179769218083

LEITE, Priscyla Ferreira Pequeno. FREIRE, Ágatha Iara Mineiro Moura. RIBEIRO, Samira

Porto de Almeida. CABRAL, Lineyde Nobre. GUILHERME, Jefferson Pereira. Incidência de aleitamento materno no momento da alta da terceira etapa do método canguru da Maternidade Ana Braga. Revista de Ciências da Saúde da Amazônia, 2org. http://repositorioinstitucional.uea.edu.br//handle/riuea/I299

LOTTO, CR; LINHARES, MBM. Contato "Pele a Pele" na Prevenção de Dor em Bebês Prematuros: Revisão Sistemática da Literatura. Trends Psychol. vol.26 nํㅜ․ Ribeirão Preto Oct./Dec. 2018. https://doi.org/I0.9788/TP2018.4-oIPt

MAIA, JA et al. Método Canguru: a importância da família na recuperação do recémnascido de baixo peso. Rev. Enfermagem em Foco. Brasília, 2012.

SANTOS, Maria Helena. FILHO, Francino M. de Azevedo. Benefícios do método mãe canguru em recém-nascidos pré-termos ou baixo peso: uma revisão da literatura. Universitas: Ciências da Saúde, Brasília, v. I4, n. I, p. 67-76, jan./jun. 2016. 
PINAFFI, L. P. F. Método Canguru: intervenção humanizada do enfermeiro em unidade de terapia intensiva neonatal. Monografia. Faculdade de Educação e Meio Ambiente $\begin{array}{llll}\text { FAEMA. } & \text { Ariquemes, } & \text { RO, }\end{array}$ http://repositorio.faema.edu.br:8ooo/jspui/handle/r23456789/2304

PRODANOV, Cleber Cristiano; FREITAS, Ernani Cesar de. Metodologia do trabalho científico: métodos e técnicas da pesquisa e do trabalho acadêmico. 2a edição, Novo Hamburgo: Feevale, 2013.

SILVA, R. A; BARROS, M. C. NASCIMENTO, M. H. M. Conhecimentos de técnicos de enfermagem sobre o método canguru na unidade neonatal. Rev Bras Promoç Saúde, Fortaleza, 27(I): 124-130, jan./mar., 2014 125. https://doi.org/10.5020/2375

SOUZA, DB. et al. O papel do enfermeiro no programa mãe-canguru e seus benefícios para o prematuro: uma pesquisa bibliográfica. Trabalho de Conclusão de Curso (Bacharelado em Enfermagem)- Faculdade Paraense de Ensino. Belém, p.4I. 2016.

VENANCIO, S. I. ALMEIDA, H. Método Canguru: aplicação no Brasil, evidências científicas e impacto sobre o aleitamento materno. Rev. J. Pediatr. Rio de Janeiro 2004. 